\title{
Day-of-the-Week Effect on Stock Market Return and Volatility: Evidence from Indian Stock Market
}

\author{
Papia Mitra ${ }^{1}$ \\ ${ }^{I}$ (Assistant Professor, Department of Commerce, J.D. Birla Institute, Kolkata, India
}

\begin{abstract}
The present paper tries to investigate the presence of the significant Day-of-the-Week effect in Indian Stock Market for the period covering from January 2000 to December 2015 using daily closing prices. The Dayof-the-Week effect assumes significance particularly because of the integration of the Indian financial market to the global market since the mid-1990s. The BSE Sensex and the NSE Nifty are mostly the representatives for looking at the behavior of the Indian financial market in a macroeconomic setup and hence they are included for analysis. In order to fulfill the objectives the paper has incorporated the GARCH model specifications where a conditional variance term is included to eliminate the problem of heteroscadasticity of the residual term. The empirical results suggest that there exists no Day-of-the-Week effect on the stock return of Sensex and Nifty indexes. However, the volatility on Tuesday is statistically significant to explain the variation in the expected stock return.
\end{abstract}

Keywords - Market Risk Factor, Conditional variance, Optimal Lag-length, ARCH-LM Test, Generalized Autoregressive Conditional Heteroscadasticity.

\section{Introduction}

The stock returns vary significantly across the calendar, popularly known as the day-of-the-week effect, or month-of-the-year effect or the holiday effect. Much effort has been given by the researchers to find out the significance of calendar effects (Kiymaz et al. 2003; Berument et. al., 2001; Yucel and Yalcin, 2006; Apolinario et. al, 2006; Kenourgios et. al, 2005; Aksoy et. al, 2012, Chia et al, 2008). This Chapter focusses on the day-of-the-week (DOW) effect in the Indian stock market. The DOW effect assumes significance particularly because of the integration of the Indian financial market to the global market since the mid-1990s. The BSE Sensex and the NSE Nifty are mostly the representatives for looking at the behavior of the Indian financial market in a macroeconomic setup. We have utilized the time series data on these two indices on daily basis covering the period from January 2, 2000 to December 31, 2015.

Many studies (Kiymaz et al. 2003, Berument and Kiymaz, 2001; Yucel and Yalcin, 2006; Apolinario et. Al, 2006; Kenourgios et. al, 2005; Aksoy et. al, 2012, Chia et al, 2008) have observed that the mean returns on Mondays are significantly lower than the mean returns on any other days of the week. This implies that the stock returns are time varying, i.e. the stock returns change with the days of the week as well as conditionally heteroskedastic, i.e the variances of the stock returns are also time dependent or vary across the days of the week. One reason of this is that the individuals have a high tendency to sell on Monday than on other days of the week due to lowest trading volume on that day. The individuals also behave in pessimistic manner on Mondays and optimistic manner on Fridays. Hence, they have a tendency to sell on Mondays and purchase on Fridays. Also on Fridays the individuals can able to fetch enough information regarding the stock market after the completion of four days in the week. This is known as the Information Processing Hypothesis. Certain other reasons are influence of public (macroeconomic and political news) and private information that affect the stock return as well as the volatility in stock return across the days of the week. This is called the weekend effect. However, some other studies (Boudoukh $\mathbf{J}$ et. al., 1994) claimed that the days on which the news are identified are 25-30 percent more likely to be associated with extreme returns (either very high or very low stock returns), whereas, the days where no news are identified are more associated with moderate stock returns.

However, Basher and Sadorsky (2006) investigated the DOW effect on nineteen emerging markets covering the period from December 31, 1992 and October 31, 2003 taking into account the market risk factors provided by the excess returns of the MSCI world stock market index. However, it is defined in different ways in five different regression models. Moreover, it is also allowed to vary across the days of the week. However, the empirical results claim absence of DOW effect in most of the concerned stock markets even after adjusting the market risk factors. However, different models give us different results but the overall day of the week effect is present in Philippines, Pakistan and Taiwan even after adjusting for the market risk. Hence, some emerging stock markets do exhibit strong day-of-the-week effects even after accounting for conditional market risk factor.

However, Yucel E.M. \& Yalcin Y (2006) examines the day-of-the-week (DOW) effect on return and volatility equations of the stock markets of 20 emerging market economies covering the Pacific-rim and the post-communist states using the EGARCH-M (exponential generalized autoregressive conditional 
heteroskadasticity-in-mean) model specification. The time period varies for each stock index as per availability of the data. The EGARCH-M framework allows capturing the DOW effect and also the possible asymmetries in the variance of the stock return. However, negative surprises seem to increase volatility more than positive surprises do. A lower stock price reduces the value of the equity and thus, could increase the risk of holding the assets. The DOW effects on returns are observed in Colombia, India, Indonesia, Israel, Poland, Russia, South Africa, Slovenia, Thailand and Turkey. When the variance-specification estimates are reconsidered, we observe some DOW effects in Bulgaria, China, Malaysia, Poland, South Korea and Thailand.

Most of the studies of the European stock markets claim for the inexistence of the DOW effect on the stock market return on most of the stock indexes, though the existence of abnormal volatility in the equation of conditional variance was observed. A seasonal effect was observed on Mondays for the French and Swedish markets. The Swedish markets also reflect a significantly higher return on Fridays compared to the remaining days of the week. The period covered is from July 2, 1997 to March 22, 2004 (Apolinario et. al; 2006). The Athens Stock Exchange exhibits the DOW effect in both return and volatility covering the period 1995-2000 with the general index having significantly higher volatility on Mondays, and the bank index having the maximum volatility on Fridays, while the FTSE-40 and the miscellaneous indices have significantly lower volatility on Fridays and Tuesdays respectively (although very close to zero). However, the estimated coefficients of the conditional variance of the returns indicate the highest volatility on Mondays for the general index (2001-2004) and the FTSE-20 index (2001- 2004) and on Thursday for the FTSE-40 index (2001-2004). The lowest volatility occurs on Fridays for the general index (1995-2000), the bank, FTSE-20 and FTSE-40 indices (2001-2004), on Thursdays for general index (2001-2004), the bank and insurance indices (1995-2000), and on Tuesdays for the miscellaneous index (1995-2000). With the exception to that of the general and insurance indices on Thursdays, all the results are statistically significant, although very close to zero (Kenourgios et. al., 2005).

Tevdovski D et. al. (2012) examined the day of the week effect considering five countries of SouthEastern Europe (Bosnia and Herzegovina, Bulgaria, Croatia, Macedonia and Serbia) covering the period 2006 to 2011. The significant weekend effect is found only in Croatian and Bulgarian Stock Market. It is found that mean daily return on Monday of all the five stock indices is negative. However, the lower Monday mean daily returns in Macedonian stock exchange index are not statistically significant. However, mean daily returns in Serbia and Bosnia on Tuesday are lower than mean daily return on Monday, but also without statistical significance. However, one of the limitations of the paper is that it has not considered the Day-of-the-Week effect on volatility in stock returns.

Some other European countries like Portugal, Italy, Greece, Spain and Ireland exhibit the DOW effect even in the financial crisis period. For Italy all days of the week are statistically significant as well as negative. The returns on Friday are higher than the returns on Monday. When the modified GARCH $(1,1)$ is estimated for Italy, all the coefficients for volatility equation are insignificant. For Spain only Monday and Tuesday are statistically significant and negative. Although insignificant, the returns on Friday are higher than the returns on Monday. When the modified GARCH $(1,1)$ is estimated for Spain, all the coefficients for volatility equation except Thursday are insignificant (Aksoy et. al., 2012).

The selected countries covering the Asia-Pacific rim (Taiwan and Singapore) exhibit significant DOW effect characterized by negative Monday and positive Friday effects in the period January 2000 to December 2006. However, Hong Kong and South Korea do not exhibit significant DOW effect. The Monday returns are consistently negative for all the concerned indexes whereas Friday returns are always positive. Moreover, adjustment of the equity market risk factor changes the empirical result with DOW effect persisting only in Taiwan (Chia et al; 2008).

Botswana, Egypt, Ghana, Nigeria and South Africa are examined for the existence of DOW effect. The results confirm the existence of DOW effect on stock returns of all the concerned countries. Moreover, these stock markets have accounted a tendency of high volatility. However, some other indicators of volatility such as Standard Deviation, Coefficient of Variation and Variance are also very high for the stock markets of Botswana and Nigeria. However, in Egypt, Ghana and South Africa the daily return seasonality is not followed by high stock market volatility which implies that high return does not always mean that the risk associated with the investment on that stock is very high (Chukwogor, 2007).

Smirlock M et.al. (1986) examined the day of the week and intraday effects considering the hourly values of the Dow Jones Industrial Average, USA. However, the entire period was divided into three subperiods- January 1, 1963-February 9, 1968, February 10, 1968- September 30, 1974 and October 1, 1974-1983. However, for the first sub-period, the return from Friday close to Monday open was positive. Over the 19681974 sub-period, the non-trading weekend return is slightly negative, but the weekend effect is attributable to the statistically significant negative opening hour returns. Finally over the last sub-period, trading period returns on Monday are positive, although the returns in the opening hour are statistically significantly negative. 
However, there also occurred a significant shift in the weekend effect from a trading time to a non-trading time effect.

Berument H \& Kiymaz H (2001) analyzed the DOW effect in return and volatility equations of one of the US stock indices, S\&P 500 index covering the period of January 1973 and October 1997 using OLS, GARCH and GARCH-in-mean term specifications. Moreover, the entire period is divided into two sub-periods: pre and post-1987. The results show that the DOW effect is present in both return and volatility equations. While the highest and lowest returns are observed on Wednesday and Monday respectively, the highest and lowest volatility are observed on Friday and Wednesday. Hence, Wednesday is characterized by the highest return and the lowest volatility. Moreover, the DOW effect is present in both return and volatility equations in both the sub-periods though the patterns are different.

Among the emerging Asian markets, one of the most appealing markets is the Indian stock market. The Bombay Stock Exchange (BSE) of India is well-known as one of the oldest stock exchanges in Asia. The Sensex is generally regarded as the most popular and precise barometer of the Indian stock market. In fact, BSE has the greatest number of listed companies in the world, with 4700 listed in the third quarter of 2007. Bhattacharya K et. al. (2003) studies the stability of the day of the week effect in mean return and in conditional variance of return at the Indian capital market in a GARCH framework. It claims for the significant positive returns at the Indian capital market during the early 1990's on Friday. In fact, the analysis based on the series covering the entire sample period, shows significant positive effect on Friday as well as on Thursday. However, Monday yielded positive effect. In the two sub-periods, while Monday, Wednesday and Friday have been found to have significant negative, negative and positive effects respectively in Period 1, the same day effects have also been observed in Period 2 but with opposite signs.

Chia and Lieu (2010) examines the existence of day of the week effect and asymmetrical behavior in the Bombay Stock Exchange over the pre-9/11 and post 9/11 sub-periods using the EGARCH and EGARCH•M models. However, the OLS results show that Monday is significantly different from zero in BSE during pre9/11 sub-period, but is insignificant during post-9/11 sub-period. There is no evidence of day-of-the-week effect in the post 9/11 sub-period. However, there exists significant DOW effect in both the sub-periods after controlling for time-varying variance and asymmetrical market behavior.

\section{Objectives of the Paper}

The objectives of this chapter is to investigate the DOW effect in the stock market return and volatility by examining the BSE Sensex and NSE Nifty Fifty indexes for the period from 2000 to 2015 using daily closing stock prices. Hence a conditional variance framework is used to find out the presence of DOW effect in return and volatility equations. However, in order to fulfill the objectives, the analysis is planned in the following way:-

- Finding out the descriptive statistic properties for the days of the week, i.e., to check for the normality of the returns for both the indexes.

- To test for the non-stationarity of the stock return of both the indexes using unit root (ADF) test.

- Investigating the presence of Day-of-the-Week (DOW) effect in stock market return as well as the volatility of both the indexes [BSE Sensex and NSE Nifty].

\section{Data Source and Research Methodology}

The study considers the two major stock indexes of the two major stock exchanges of the Indian stock market: BSE Sensex (Bombay Stock Exchange) and CNX Nifty Fifty (National Stock Exchange).

The paper covers the period between January 2000 and December 2015. This is because it tries to analyze the presence of day-of-the-week effect on the aforesaid stock indices in the last fifteen years of the ongoing century. All the data are expressed in local currencies (Indian Rupees).

The data are collected from official websites of Bombay Stock Exchange and National Stock Exchange.

The returns $\left(R_{t}\right)$ are calculated as the first differences in the natural logarithms of the stock market indexes.

$$
\mathbf{R}_{\mathrm{t}}=\left[\log \left\{\mathbf{P}_{\mathrm{t}}\right\}-\log \left\{\mathbf{P}_{(\mathrm{t}-1)}\right\}\right]^{* 100}
$$

where $\mathrm{P}_{\mathrm{t}}$ is the closing price of the index in $\mathrm{t}$-th period and $\mathrm{P}_{(\mathrm{t}-1)}$ is the closing price of the index in (t1)-th period. [Yalcin \& Yucel, 2006; Chia and Lieu, 2010].

The present study tries to find out the Descriptive Statistics of returns of the concerned stock indices/prices considering the overall period (2000 to 2015). The parameters such as mean return (in percentage), standard deviation (risk in percentage), skewness (asymmetry), kurtosis (peakedness), Jarque-Bera test of normality are applied to find out the stochastic properties of the data series. The last three parameters are used in order to find out the presence of normality in the frequency distribution.

Further, a stationary time series is one whose statistical properties like mean, variance and autocorrelation are time-invariant, i.e. the statistical properties will be the same in future as they have been in the past. These statistical descriptors are useful to determine the future behavior of any data series provided the 
series is stationary. Hence, non-stationary time series data give certain misleading results. To avoid such problem of non-stationarity in data series, we first subject the data to stationarity test by using Augmented Dickey Fuller (ADF) test.

\subsection{Hypotheses to be tested:}

The following hypotheses are tested:

Hypothesis 1: There are no differences in the average return on the stock indices across the days of the week. Hypothesis 2: There are no differences in the volatility of the stock indices across the days of the week.

\subsection{Model Specification:}

Most studies investigating the DOW effect in returns employ the standard OLS methodology by regressing returns on the daily dummy variables. However, the use of this methodology has certain limitations in the sense that errors in the model may be autocorrelated leading to misleading results. The second limitation is that the error variances may not be constant overtime.

$$
R_{t}=\alpha_{0}+\alpha_{1} D_{1 t}+\alpha_{2} D_{2 t}+\alpha_{3} D_{3 t}+\alpha_{4} D_{4 t}+\sum_{i} \beta_{i} R_{t-1}+\varepsilon_{t} \ldots \ldots \ldots \text {. Model I }
$$

Where $D_{1 t}, D_{2 t}, D_{3 t}$ and $D_{4 t}$ are the dummy variables for Tuesday, Wednesday, Thursday and Friday at the $\mathrm{t}$-th period and $\mathrm{n}$ is the lag-order. The lagged values of the return variable are included to eliminate the possibility of having autocorrelated errors.

The use of OLS methodology, however, has two drawbacks. First, errors in the model may be autocorrelated resulting in misleading inferences. The second drawback is that error variances may not be constant over time. To address the autocorrelation problem, we can include lagged values of the return variable in the equation (Kiymaz H \& Berument H, 2003; Apolinario R.M.S et. al., 2006). Also the residuals are possibly non-normal, the issue of heteroscedasticity may arise and outliers with high/low value of return may distort the overall picture (Abdalla S.Z.S, 2012).

The second model consists of the following two equations:-

$$
\begin{aligned}
& R_{t}=\alpha_{0}+\alpha_{1} D_{1 t}+\alpha_{2} D_{2 t}+\alpha_{3} D_{3 t}+\alpha_{4} D_{4 t}+\sum_{i} \beta_{i} R_{t-1}+\lambda h_{t}+\varepsilon_{3 t} \\
& h_{t}^{2}=V_{c}+V_{l a} \epsilon_{t-1}^{2}+V_{l b} h_{t-1}^{2}
\end{aligned}
$$

where ' $\lambda$ ' is the measure of the risk premium. If the risk premium is positive, then the risk averse agents must be compensated to accept higher risk.

In the next model, we model the conditional variability of stock returns by incorporating the DOW effect into the volatility equation. Thus, we allow the constant term of the conditional variance equation to vary for each day.

$$
\begin{gathered}
\mathrm{R}_{\mathrm{t}}=\alpha_{0}+\alpha_{1} \mathrm{D}_{1 \mathrm{t}}+\alpha_{2} \mathrm{D}_{2 \mathrm{t}}+\alpha_{3} \mathrm{D}_{3 \mathrm{t}}+\alpha_{4} \mathrm{D}_{4 \mathrm{t}}+\sum \beta_{\mathrm{i}} \mathrm{R}_{\mathrm{t}-\mathrm{I}}+\lambda \mathrm{h}_{\mathrm{t}}+€_{4 \mathrm{t}} \\
\mathrm{h}_{\mathrm{t}}^{2}=\mathrm{V}_{\mathrm{c}}+\mathrm{V}_{1} \mathrm{D}_{1 \mathrm{t}}+\mathrm{V}_{2} \mathrm{D}_{2 \mathrm{t}}+\mathrm{V}_{3} \mathrm{D}_{3 \mathrm{t}}+\mathrm{V}_{4} \mathrm{D}_{4 \mathrm{t}}+\mathrm{V}_{\mathrm{j} 1} €_{\mathrm{t}-1}^{2}+\mathrm{V}_{1 \mathrm{~b}} \mathrm{~h}_{\mathrm{t}-1 \ldots \ldots . \text { MODEL III }}^{2}
\end{gathered}
$$

Hence,

$\mathrm{h}_{\mathrm{t}}$ : The standard deviation of the present period error term;

$\epsilon_{\mathrm{t}-1}^{2}$ : Last period's volatility (the ARCH term);

$\mathrm{h}_{\mathrm{t}-1}^{2}$ : Last period's variance (the GARCH term).

Hence, we employ two different types of specifications for the return and volatility equations. The first one investigates the DOW effect for only the return equation by using the GARCH $(1,1)$ specifications. The second model incorporates the DOW effect for both the return and volatility equations by using the modifiedGARCH $(1,1)$ specification. For GARCH $(1,1)$ model, $\mathrm{V}_{\mathrm{c}}$ must be positive and the sum of the coefficients in the conditional variance equation, $\left(\mathrm{V}_{\mathrm{j} 1}+\mathrm{V}_{1 \mathrm{~b}}\right)$, must be less than unity for the process to be stationary. This sum also indicates the level of persistence in the volatility shocks. A sum close to unity is favorable for providing evidence of a persistent volatility process [Aksoy M et. al. 2012].

If the residual term were autocorrelated, ARCH-LM tests would suggest the presence of heteroskadasticity in the residual term even if the residuals were homoscadastic. Monday's dummy variable is omitted from the equation to avoid the dummy variable trap. Thus, the error terms now have zero mean and a time changing variance of $\mathrm{h}_{\mathrm{t}}^{2}\left[€ \sim\left(0, \mathrm{~h}_{\mathrm{t}}^{2}\right)\right]$. 


\subsection{Descriptive Statistics}

\section{Empirical Findings}

Table I: Descriptive Statistics Results of Sensex and Nifty

\begin{tabular}{|c|c|c|c|c|c|c|}
\hline & \multicolumn{5}{|c|}{ BSE SENSEX } & \multirow[b]{2}{*}{ All Days } \\
\hline & Monday & Tuesday & Wednesday & Thursday & Friday & \\
\hline Mean & 0.01 & 0.01 & 0.04 & 0.01 & 0.02 & 0.02 \\
\hline Std Dev & 0.16 & 0.64 & 0.62 & 0.62 & 0.73 & 0.68 \\
\hline Skewness & 0.16 & -0.30 & -0.08 & -0.25 & -0.51 & -0.18 \\
\hline Kurtosis & 14.70 & 7.13 & 5.91 & 5.40 & 8.14 & 9.92 \\
\hline $\begin{array}{c}\text { Jarque-Bera } \\
\text { Estimate }\end{array}$ & 4522.91 & 576.40 & 279.61 & 196.17 & 884.02 & 7877.44 \\
\hline P-Value & $0.00^{*}$ & $0.00^{*}$ & $0.00 *$ & $0.00^{*}$ & $0.00 *$ & $0.00 *$ \\
\hline \multirow[t]{3}{*}{ Obs } & 792 & 792 & 789 & 783 & 773 & 3929 \\
\hline & \multicolumn{5}{|c|}{ NSE NIFTY } & \\
\hline & Monday & Tuesday & Wednesday & Thursday & Friday & All Days \\
\hline Mean & 0.005 & 0.002 & 0.05 & 0.01 & 0.02 & 0.02 \\
\hline Std Dev & 0.78 & 0.63 & 0.62 & 0.62 & 0.72 & 0.67 \\
\hline Skewness & 0.01 & -0.23 & 0.08 & -0.34 & -0.79 & -0.26 \\
\hline Kurtosis & 16.48 & 7.23 & 5.56 & 5.20 & 10.23 & 11.15 \\
\hline $\begin{array}{l}\text { Jarque-Bera } \\
\text { Estimate }\end{array}$ & 5970.16 & 596.80 & 216.42 & 173.69 & 1766.50 & 11017.85 \\
\hline P-Value & $0.00 *$ & $0.00 *$ & $0.00 *$ & $0.00 *$ & $0.00 *$ & $0.00 *$ \\
\hline Obs & 788 & 790 & 786 & 784 & 773 & 3921 \\
\hline
\end{tabular}

Note: * indicate rejecting $H_{0}$ at $5 \%$ level of significance

Here, we analyze the stochastic properties of the stock return of both the indexes-BSE Sensex and CNX Nifty Fifty from the period from 2000 to 2015. However, the entire return series is divided into the days of the week and the stochastic properties of the return series are analyzed for each of the days of the week. However, it is found that both the indexes exhibit the highest average return on Wednesday (0.04 for Sensex and 0.05 for Nifty). For both the indexes, the returns on all the days of the week are positive. Monday, Tuesday and Thursday exhibit same rate of return (0.01) for Sensex which is the lowest return. The lowest return is realized on Tuesday for Nifty (0.002). Moreover, Friday and Monday are the days of highest volatility for Sensex and Nifty respectively (0.73 and 0.78 respectively). Monday exhibits least volatile return in Sensex $(0.16)$ which is very low compared to the other days of the week. However, the volatility does not vary too much across the days of the week for Nifty.

However, the Skewness and Kurtosis are considered to verify the normality of the frequency distribution in each of the two data series. As stated earlier in the research methodology, the pre-requisite condition for the normality of the frequency distribution is that the frequency distribution should be symmetric (zero skewness) and the peakedness or the value of the kurtosis equal to 3. The Jarque-Bera test of normality justifies statistically that none of the frequency distributions are normal as the null hypothesis of normality of the frequency distribution is rejected at both 5 percent and 1 percent levels of significance. But in spite of that we work with the original data series itself as in all the stocks, the sample size is large (very close to 4000). Thus the econometric results will not turn out to be misleading.

\subsection{Unit Root Test: Daily Return of Sensex and Nifty}

Table II: Unit Root Test Results of Sensex and Nifty

\begin{tabular}{|c|c|c|}
\hline & BSE SENSEX & NSE NIFTY \\
\hline ADF Estimated Test Statistic & -54.36 & -57.42 \\
\hline p-value & $0.00^{*}$ & $0.00^{*}$ \\
\hline
\end{tabular}

Note: * indicate rejecting $H_{0}$ at $5 \%$ level of significance

The return series for both the indexes are tested for the presence of unit root. The study applies Augmented Dickey-Fuller test for the presence of non-stationarity. However, for both the indexes, the absolute values of the estimated t-statistic exceed 2 such that the null hypothesis of the presence of unit root is rejected. Moreover, the p-values also turn out to be lower than 0.01 and 0.05 such that the null hypothesis of the presence of unit roots is rejected at both $5 \%$ and $1 \%$ levels of significance. Thus, the return series for both the indexes is stationary at level itself. The reason is that return is calculated as the first difference of the closing stock prices of the two consecutive days. Hence, it is integrated of order zero [I (0)] such that any empirical analysis can be done on the initial return series itself. Hence, the transformation of the return series is not required. 
4.2.1. Unit Root Test of the Daily Stock Return across the Days-of-the-Week (DOW) Table III: Unit Root Test Results across the DOW

\begin{tabular}{|c|c|c|c|c|c|}
\hline & \multicolumn{5}{|c|}{ BSE SENSEX } \\
\hline & Monday & Tuesday & Wednesday & Thursday & Friday \\
\hline Estimated ADF Statistic & -30.30 & -29.09 & -12.92 & -28.10 & -25.71 \\
\hline \multirow[t]{3}{*}{ p-value } & 0.00 & 0.00 & 0.00 & 0.00 & 0.00 \\
\hline & \multicolumn{5}{|c|}{ CNX NIFTY FIFTY } \\
\hline & Monday & Tuesday & Wednesday & Thursday & Friday \\
\hline Estimated ADF Statistic & -30.32 & -27.92 & -29.17 & -28.54 & -25.82 \\
\hline p-value & 0.00 & 0.00 & 0.00 & 0.00 & 0.00 \\
\hline
\end{tabular}

Note: * indicate rejecting $H_{0}$ at $5 \%$ level of significance

The return series for both the indexes are tested for the presence of unit root across the days of the week. The study applies Augmented Dickey-Fuller test for the presence of non-stationarity. However, for both the indexes, the absolute values of the estimated t-statistic exceed 2 such that the null hypothesis of the presence of unit root is rejected. Moreover, the p-values (represented in the parentheses) also turn out to be lower than 0.01 and 0.05 such that the null hypothesis of the presence of unit roots at both $5 \%$ and $1 \%$ levels of significance. Thus, the return series for both the indexes is stationary at level itself. The reason is that return is calculated as the first difference of the closing stock prices of the two consecutive days. Hence, it is integrated of order zero [I (0)] such that any empirical analysis can be done on the initial return series itself. Hence, the transformation of the return series is not required.

\subsection{Day-of-the-Week Effect in Return Equation: OLS Specification}

Table IV: Day-of-the-Week Effect in Return Equation (OLS) Results

\begin{tabular}{|c|c|c|}
\hline & BSE SENSEX & NSE NIFTY \\
\hline \multicolumn{3}{|c|}{ Panel A: Estimates of Return Equation } \\
\hline \multicolumn{3}{|c|}{ Return Equation } \\
\hline Monday (Constant) & $0.04(0.46)$ & $-0.08(0.15)$ \\
\hline Tuesday & $0.03(0.75)$ & $0.03(0.67)$ \\
\hline Wednesday & $0.06(0.48)$ & $0.17(0.02) *$ \\
\hline Thursday & $0.05(0.50)$ & $0.07(0.36)$ \\
\hline Friday & $-0.06(0.45)$ & $-0.01(0.85)$ \\
\hline Return(-1) & $0.08(0.03) *$ & $0.10(0.005)^{*}$ \\
\hline DW d-statistic & 2.01 & 2.00 \\
\hline \multicolumn{3}{|l|}{ Panel B: ARCH-LM Test } \\
\hline \multicolumn{3}{|l|}{ Lags } \\
\hline 5 & $27.37(0.00)^{*}$ & $20.65(0.00)^{*}$ \\
\hline 10 & $14.51(0.00)^{*}$ & $12.10(0.00)^{*}$ \\
\hline 15 & $10.84(0.00)^{*}$ & $11.10(0.00)^{*}$ \\
\hline 20 & $9.16(0.00) *$ & $8.70(0.00) *$ \\
\hline 25 & $7.74(0.00)^{*}$ & $7.05(0.00)^{*}$ \\
\hline
\end{tabular}

Note: * implies rejecting Ho at $5 \%$ level of significance.

The results show that there exists no Day-of-the-Week (DOW) effect on Sensex return. The values in the parentheses represent the p-values. However, the return is positive for all the days of the week except on Friday, where it is the least. However, it is the highest on Wednesday. On the other hand, Nifty exhibits Wednesday effect. Wednesday return is the highest among all the days of the week. It is the least on Monday though it is not statistically significant. However, the Durbin-Watson d-statistic claims that both the indexes' return series are free from serial correlation (both are equal to 2).

To confirm the use of the GARCH methodology, it is very important test for ARCH effects in the residual series. The study applies ARCH-LM test up to 25 lags. However, the results provide strong evidence for rejecting the null hypothesis of no ARCH effects for lags included. Rejecting the null hypothesis indicate that the variance of the residual series is not constant. Since, the findings of the OLS model indicate the presence of $\mathrm{ARCH}$ components in squared variances, we construct the conditional variance of the return equation as a $\operatorname{GARCH}(1,1)$ process and re-estimate the return equation with the conditional variance equation jointly. 


\subsection{Day-of-the-Week Effect in Return: GARCH $(1,1)$ Model Specification}

Table V: Day-of-the-Week Effect in Return Equation

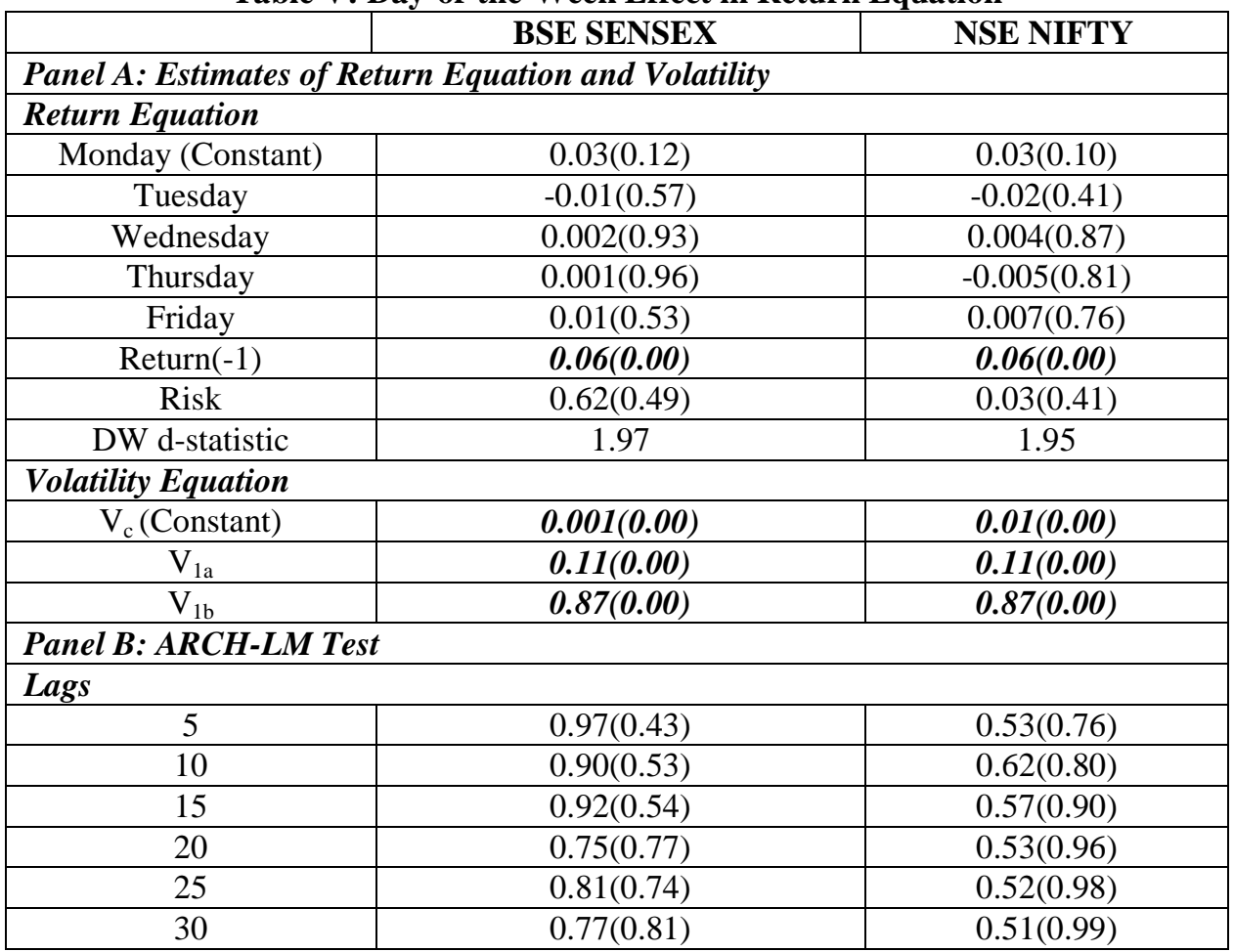

Note: * indicate rejecting $\mathrm{H}_{0}$ at $5 \%$ level of significance

Table V reports the day of the week (DOW) effect and stock market volatilities for NSE Nifty and BSE Sensex. Four dummy variables are incorporated for representing five days of the week. Also the lagged return variable is included and the optimum number of lags is obtained by the four lag-length criteria (AIC, SIC, HIC and FPEC). However, all these criteria claim the optimum lag-length equal to one. Thus, the model incorporates only one period lagged value of return. Moreover, the volatility equation considers three estimated coefficients of the GARCH $(1,1)$ model specification. $\mathrm{V}_{\mathrm{c}}$ is the estimated coefficient of the constant term for the conditional variance equation, while V1a is the estimated coefficient of the lagged value of the squared residual term. $\mathrm{V}_{1 \mathrm{~b}}$ represents the lagged value of the conditional variance.

Panel A considers the estimates of the return and volatility equations. From the return equation, it is clear that none of the days of the week is statistically significantly in explaining variation in the expected return. Hence, the days of the week cannot determine significantly the change in expected return. However, the return on Monday is positive (0.03) and turns out to be the same in both the indexes. Tuesday exhibits negative return for both the indexes and it is equal to -0.02 . For Sensex, except Tuesday all the other days yield positive return. For Nifty, Tuesday and Thursday both exhibit negative return ( -0.02 and -0.005 respectively). For both the indexes, Monday and Tuesday exhibit the highest and lowest return respectively ( 0.03 and -0.01 for Sensex and 0.03 and -0.02 for Nifty). However, the risk factors though positive yet not statistically significant implying that it is not a significant determinant of expected return. However, the lagged return variable is statistically significant for both the return series.

In the volatility equation of panel A, the coefficients of the GARCH $(1,1)$ specification are estimated. All the estimated coefficients (both intercept and slope) are positive and statistically significant implying that stock market volatility is an important determinant of the stock return and higher volatility leads to higher return. Hence, the higher risk due to higher volatility is compensated by a higher return out of investment by the investors. Moreover, the sum of the estimated slope coefficients turns out to be less than one $\left(\mathrm{V}_{1 \mathrm{a}}+\mathrm{V}_{1 \mathrm{~b}}<1\right)$ implying that the process is stationary.

Panel B considers the results of the ARCH-LM test of presence of ARCH effect in the return series. For testing 5, 10, 15, 20, 25 days lags are considered for estimating the F-statistic. However, the p-values are greater than 0.01 and 0.05 such that the null hypothesis of no $\mathrm{ARCH}$ effect is accepted at both 1 percent and 5 percent levels of significance. Hence, there is no ARCH effect in the model. This implies that the residual terms have constant variances. The Durbin-Watson d-statistic also turns out to be very close to 2 , indicating absence of serial correlation between the residual terms of the two consecutive time period. 
Day-of-the-Week Effect on Stock Market Return and Volatility: Evidence from Indian Stock Market

4.5. Day-of-the-Week Effect in Return and Volatility Equations: Modified-GARCH Model Specification

Table VI: Day-of-the-Week Effect in Return and Volatility Equations

\begin{tabular}{|c|c|c|}
\hline & BSE SENSEX & NSE NIFTY \\
\hline \multicolumn{3}{|c|}{ Panel A: Estimates of Return and Volatility Equations } \\
\hline \multicolumn{3}{|l|}{ Return Equation } \\
\hline Monday (Constant) & $0.003(0.12)$ & $0.03(0.13)$ \\
\hline Tuesday & $-0.02(0.48)$ & $-0.02(0.34)$ \\
\hline Wednesday & $-0.005(0.84)$ & $-0.002(0.92)$ \\
\hline Thursday & $-0.006(0.82)$ & $-0.01(0.67)$ \\
\hline Friday & $0.01(0.68)$ & $0.004(0.88)$ \\
\hline Return(-1) & $0.07(0.00)$ & $0.07(0.00)$ \\
\hline Risk & $0.03(0.47)$ & $0.03(0.36)$ \\
\hline \multicolumn{3}{|l|}{ Volatility Equation } \\
\hline $\mathrm{V}_{\mathrm{c}}$ (Constant) & $0.03(0.008) *$ & $0.04(0.001) *$ \\
\hline $\mathrm{V}_{1 \mathrm{a}}$ & $0.11(0.00)^{*}$ & $0.11(0.00)^{*}$ \\
\hline $\mathrm{V}_{1 \mathrm{~b}}$ & $0.87(0.00)^{*}$ & $0.87(0.00)^{*}$ \\
\hline Tuesday & $-0.07(0.00)^{*}$ & $-0.09(0.00)^{*}$ \\
\hline Wednesday & $-0.009(0.58)$ & $-0.02(0.25)$ \\
\hline Thursday & $-0.03(0.08)$ & $-0.02(0.15)$ \\
\hline Friday & $0.0004(0.83)$ & $-0.006(0.76)$ \\
\hline DW d-statistic & 1.97 & 1.97 \\
\hline \multicolumn{3}{|l|}{ Panel B: ARCH-LM Test } \\
\hline \multicolumn{3}{|l|}{ Lags } \\
\hline 5 & $1.22(0.30)$ & $0.79(0.56)$ \\
\hline 10 & $1.01(0.43)$ & $0.78(0.65)$ \\
\hline 15 & $0.99(0.46)$ & $0.70(0.79)$ \\
\hline 20 & $0.80(0.72)$ & $0.62(0.90)$ \\
\hline 25 & $0.81(0.73)$ & $0.57(0.95)$ \\
\hline 30 & $0.77(0.81)$ & $0.55(0.98)$ \\
\hline
\end{tabular}

Note: * indicate rejecting $H_{0}$ at $5 \%$ level of significance

In the above table (Table VI), the conditional variance of the returns is then allowed to vary across the days of the week by framing the conditional variance of the return equation as a modified GARCH model. This is done in order to detect the existence of a DOW effect in volatility. Hence, the dummy variable for Mondays is omitted to avoid dummy variable trap and four new day-of-the-week dummy variables are incorporated in the model. In this model specification, we re-examine both the returns and conditional variance equations. In this model also none of the days exhibit statistically significant average returns for both Sensex and Nifty implying that there is no such Day-of-the-Week effect on stock market return. Friday and Monday exhibit maximum average return for Sensex and Nifty respectively. In both the indexes, Monday and Friday exhibit positive average returns. However, all the other days of the week exhibit negative returns. The coefficients of the conditional standard deviation of the return equation (risk) are positive but statistically insignificant for both the indexes. This would suggest that the investors want get compensated with higher returns for holding riskier assets.

The estimated volatility coefficients for the constant terms, as well as slope terms, are positive and statistically significant. This satisfies the non-negativity of the conditional variances. The volatility on Tuesday is statistically significant for both the indexes. The highest volatility occurs on Friday for Sensex, whereas, both Wednesday and Thursday exhibit highest volatility for Nifty. Friday is the only day where volatility is positive for Sensex whereas, all the days of the week in Nifty exhibit negative volatility.

The ARCH-LM test in panel B of each stock indexes indicates absence of a statistically significant ARCH effect in any of the stocks. Hence, the ARCH-LM test on the residual indicates absence of heteroscadasticity. Hence, the null hypothesis of no ARCH effect is accepted at both 1 percent 5 percent levels of significance. This implies that the residual terms have constant variances. The Durbin-Watson d-statistic also turns out to be very close to 2 , indicating absence of serial correlation between the residual terms of the two consecutive time period. 


\section{Conclusion}

The main objective of the paper is to investigate the Day-of-the-Week (DOW) effect on stock market return and volatility of the two selected indexes-BSE Sensex and NSE Nifty Fifty computing daily closing (inter-day) returns from January 2, 2000 to December 31, 2015 by formulating GARCH and Modified-GARCH model specifications. The statistical properties of the data series (interday return of BSE Sensex and NSE Nifty Fifty) claim that they are integrated of order zero, i.e. they are stationary at level itself. Hence, any statistical analysis can be done on the original series itself. However, the descriptive statistics of both the data series claim that Wednesday exhibits the highest average return for both Nifty Fifty and Sensex. However, Nifty yields a higher return on Wednesday than that of Sensex. However, Friday and Monday are the most volatile days for Sensex and Nifty respectively. However, in the first model specification, apart from the four dummy variables and a lagged variable of return, conditional variance of the residual term is also incorporated. In this model, none of the days of the week is statistically significant to explain the expected return of both Sensex and Nifty indexes. However, the risk factors though are positive, still not statistically significant. However, the estimates of $\operatorname{GARCH}(1,1)$ are positive and statistically significant, implying that the volatility factors incorporated in the model are statistically significant to explain the variation in the stock market return. In the next model specification, the conditional variance of the residual term is allowed to vary across the days of the week. This model is formulated to detect the existence of a DOW effect in volatility. In this model also, none of the days of the week are statistically significant to explain variation in stock market return for both the indexes. Moreover, the volatility on Tuesday is statistically significant for both Sensex and Nifty. The highest volatility occurs on Friday for Sensex, whereas, both Wednesday and Thursday exhibit highest volatility for Nifty. Though the stock returns vary across the days of the week, yet these days are not statistically significantly explaining the variation in the expected stock return. Hence, the changes in the days of the week cannot determine the changes in stock return. Moreover, the risk factor also does not significantly affect the stock return. Hence, the Indian Stock Market does not exhibit any such DOW effect in stock return. However, there exists significant Tuesday effect in terms of stock market volatility in both Sensex and Nifty.

\section{References}

[1] Abdalla S.Z.S, Stock Return Seasonalities: Empirical Evidence from the Egyptian Stock Market, International Review of Business Research Papers 8(2), 2012, 163-180.

[2] Aksoy M, Seçme Z.O, Karatepe S, Benli F, Day of the Week Anomaly during Financial Crisis: Portugal, Italy, Greece, Spain and Ireland. Available at: www.hippocampus.si/ISBN/978-961-6832-32-8/papers/aksoy1.pdf, 2012, 205-218.

[3] Apolinario R.M.C., Santana O.M., Sales L.J., Caro A.R. Day of the Week Effect on European Stock Markets. International Research Journal of Finance and Economics, 2, 2006, 53-70.

[4] Basher S. A and Sadorsky P, Day-of-the-Week Effects in Emerging Stock Markets, Applied Economics Letters, 13, 2006, 621-628.

[5] Berument H. and Kiymaz H, The Day of the Week Effect on Stock Market Volatility, Journal of Economics and Finance, 25(2), 2001, 181-193

[6] Bhattacharya K, Sarkar N \& Mukhopadhyay D, Stability of the Day of the Week Effect in Return and In Volatility at the Indian Capital Market: A GARCH Approach With Proper Mean Specification. Applied Financial Economics, 13, 2003, 553-563.

[7] Boudoukh J. and Richardson M. P, Industry Returns and the Fischer Effect, Journal of Finance, 49(5), 1994, 1595-1615.

[8] Charles A, the Day-of-the-Week Effects on the Volatility: The Role of the Asymmetry, European Journal of Operational Research. 202(1), 2010, 143-152.

[9] Chia R.C.J, Liew V.K.S, Wafa S.A. and Wafa S.K, Day-of-the-week effects in Selected East Asian stock markets, Economics Bulletin, 7(5), 2008, 1-8.

[10] Chia R. C. J and Liew V. K. S, Evidence on the Day-of-the-week Effect and Asymmetric Behavior in the Bombay Stock Exchange, The IUP Journal of Applied Finance, 16, 2010, 17-29.

[11] Chukwuogor C, An Econometric Analysis of African Stock Market: Annual Returns Analysis, Day-Of-The-Week Effect and Volatility of Returns. African Journal of Accounting, Economics, Finance and Banking Research, 1(1), 2007, 26- 43.

[12] Fama E.F, The Behaviour of Stock Market Prices, Journal of Business, 38, 1965, 161-178.

[13] Kenourgios D, Samitas F, Papathanasiou S, The day of the week effect patterns on stock market return and volatility: Evidence for the Athens Stock Exchange, Proceedings of the 2nd Applied Financial Economics (AFE) International Conference on Financial Economics, Samos Island, Greece, 2005, 1-14.

[14] Kiymaz H and Berument H, The Day of the Week Effect on Stock Market Volatility and Volume: International Evidence, Review of Financial Economics 12, 2003, 363-380.

[15] Mitchell J.D. and Ong L.L, Seasonalities in China's Stock Markets: Cultural or Structural? Working Paper. Monetary and Financial Systems Department, International Monetary Fund, No. WP/06/4, 2006.

[16] Quandt R.E, Tests of the Hypothesis That a Linear Regression System Obeys Two Separate Regimes, Journal of the American Statistical Association, 55, 1960, 324-330.

[17] Smirlock M and Starks L, Day-of-the-Week and Intraday Effects in Stock Returns, Journal of Financial Economics, 17, 1986, 197210.

[18] Tevdovski D, Mihajlov M, Sazdovski I, The Day of the Week Effect in South Eastern Europe Stock Markets, Annals of the Constantin Brâncuşi. University of Târgu Jiu, Economy Series, 3, 2012, 20-24.

[19] Yalcin Y. \& Yucel U.M, The Day-of-the-Week-Effect on Stock Market Volatility and Return: Evidence from Emerging Markets, Czech Journal of Economics and Finance, 56, 2006, 258-278. 